\title{
Induced Expectoration Technique
}

National Cancer Institute

\section{Source}

National Cancer Institute. Induced Expectoration Technique. NCI Thesaurus. Code C132353.

A type of expectoration procedure in which hypotonic saline is inhaled, making lung secretions easier to cough up. 